\title{
Preparation and Characterization of Activated Carbon from Pandanus candelabrum Stem
}

\author{
PAUL EGWUONWU DIM, AUGUSTINE UGOCHUKWU ILOKA \& JOSEPH \\ ONYEBUCHI OKAFOR
}

\author{
Department of Chemical Engineering, Federal University of Technology, Minna, Nigeria \\ *Corresponding author: pevdim@yahoo.com \\ Received: 23 October 2020 \\ Accepted: 18 December 2020 \\ Published: 31 December 2020
}

\begin{abstract}
Pandanus candelabrum stem, a new precursor, was used to synthesise activate carbon. The effect of sodium hydroxide, $\mathrm{NaOH}$, zinc (II) chloride, $\mathrm{ZnCl}_{2}$ and phosphoric acid, $\mathrm{H}_{3} \mathrm{PO}_{4}$, different agents on prepared adsorbents was investigated. The adsorbents were prepared with chemical agents and carbonized at $400{ }^{\circ} \mathrm{C}$ for 1 hour. Surface morphology, elemental composition and functional groups were analysed with scanning electron microscopy (SEM), energy dispersive X-ray (EDX), X-ray diffraction (XRD) and fourier transform infrared spectroscopy (FTIR), respectively. The image analysis showed the presence of both micropores and mesopores in the adsorbents. The $\mathrm{H}_{3} \mathrm{PO}_{4}$ activated carbon had the maximum surface area $\left(2648 \mathrm{~m}^{2} / \mathrm{g}\right)$, pore volume $\left(1.683 \mathrm{~cm}^{3} / \mathrm{g}\right)$ and highest adsorption for iodine and methylene blue were 541 and $105 \mathrm{mg} / \mathrm{g}$. Pandanus candelabrum stem is an alternative material that can be used to synthesis high porous adsorbent because is abundant, easy to access, inexpensive and readily available.
\end{abstract}

Keywords: Activated, adsorption, iodine number, methylene blue, Pandanus candelabrum, reagents

Copyright: This is an open access article distributed under the terms of the CC-BY-NC-SA (Creative Commons Attribution-Non-Commercial-Share Alike 4.0 International License) which permits unrestricted use, distribution, and reproduction in any medium, for non-commercial purposes, provided the original work of the author(s) is properly cited.

\section{INTRODUCTION}

The most widely used adsorbent is activated carbon, which has high surface area, adsorptive capacity and is inexpensive (Sahira et al., 2013; Yorgun \& Yildiz, 2015; Kumar \& Jena, 2017). Biomass is a natural carbon source which is used for the preparation of green adsorbents, which have several advantages over non-renewable sources. This renewable biomass is abundant, cheap, environmentally friendly and renewable (Rai et al., 2016). The application of biomass wastes for the synthesis of solid adsorbent reduces the impact of environmental pollution (Cadavid et al., 2016). One of the popular methods employed in the preparation of activated carbon is the chemical activation process (Zibrik et al., 2017). This method entails doping of carbon source with activating reagent, followed by carbonization at chosen temperature values. This will have a significant effect on the carbon matrix morphology resulting to changes in the pore structure arrangement (Nafsun et al., 2020). Which is primarily, due to interaction between carbon atoms and chemical agents such as strong acid $\left(\mathrm{H}_{3} \mathrm{PO}_{4}\right)$, base $(\mathrm{NaOH})$ or salts $\left(\mathrm{ZnCl}_{2}\right)(\mathrm{Gu} \&$ Wan, 2013; Shamsuddin et al., 2016). The chemical method exhibits a very short time and low temperature during pyrolysis process (Giraldo et al., 2018). These advantages have resulted to the production of affordable and cheaper adsorbents using chemical activation method. Recently, many researchers have use different renewable resources for the preparation of adsorbent, such as mango tree bark (Dim, 2013), Malva sylvestris (Ramavandi \& Asgari, 2018), fennel seed (Hussein \& Jasim, 2019) and kaolinite clay (Dim et al., 2020).

Pandanus stem is an agricultural by product which is mainly composed of cellulose, hemicellulose, and lignin. Therefore, Pandanus stem will be a suitable lignocellulosic biomass for preparation of porous active carbons. Pandanus candelabrum originated from Pandanus plant (Screw pine), which belongs to the family Pandanaceae which comprises about 700 species and is widely distributed in tropical and subtropical regions (Fillaeli et al., 2019). They are found in the regions of South-East Asia, Pacific islands, 
Madagascar, Indian Ocean islands, India and West Africa. It is a dioecious, small tree up to $12 \mathrm{~m}$ tall with branched trunk and aerial roots (Mario \& Hiromatsu, 2018). Pandanus tree is a multipurpose plant with different uses. It is known locally as screw pine. The leaves are used for making mats, baskets and fish traps, while the fibrous root is used for brushes (Akpabio \& Akpakpan, 2012). In traditional medicine the leaves are used for the treatment of sore throat, and bark infusions are used to cure diarrhoea, dysentery, enteritis, antispasmodic, diuretic, and stimulant properties (Baba et al., 2016). Despite of its various applications there is none for using $P$. candelabrum stem for synthesis of active adsorbent.

This work used $P$. candelabrum stem as carbon source to produce active carbon with $\mathrm{H}_{3} \mathrm{PO}_{4}, \mathrm{ZnCl}_{2}$ and $\mathrm{NaOH}$. Based on literature there is no study on activated carbons synthesized from $P$. candelabrum stem. The adsorbents were characterized in terms of functional group, elemental composition and morphology.

\section{MATERIALS AND METHODS}

\section{Materials}

Pandanus candelabrum stem, which was used as a precursor was obtained from Ogbunka, Anambra State, Nigeria. To remove impurities distilled water was used to wash the sample severally, after which it was dried for $6 \mathrm{~h}$ at $80{ }^{\circ} \mathrm{C}$. Chemical agents used were $\mathrm{H}_{3} \mathrm{PO}_{4}, \mathrm{ZnCl}_{2}$ and $\mathrm{NaOH}$.

\section{Preparation of Adsorbent}

Accurately weighed $15 \mathrm{~g}$ of pulverized Pandanus stem was impregnated with activating agents in a ratio of 1:4 (w/w) $\mathrm{H}_{3} \mathrm{PO}_{4}$, (Yorgun and Yildiz, 2015) $1: 3\left(\mathrm{w} / \mathrm{w}\right.$ ) $\mathrm{ZnCl}_{2}$ and $1: 4(\mathrm{w} / \mathrm{w}) \mathrm{NaOH}$ (Kilic et al., 2012) (Precursor: Agent) by weight for $12 \mathrm{~h}$. To ensure proper mixing and penetration of the agents into the internal structure of precursor the doping was done at $80{ }^{\circ} \mathrm{C}$ for $6 \mathrm{~h}$. After impregnation, mixtures were carbonized at $400{ }^{\circ} \mathrm{C}$ (Yorgun \& Yildiz, 2015) in nitrogen flow (200 $\mathrm{cm}^{3} / \mathrm{min}$ ) at heating rate of $10^{\circ} \mathrm{C} / \mathrm{min}$, for $1 \mathrm{~h}$ in a horizontal tube furnace (model Y02PB, Thermocraft, Inc, USA), and was cool by open air. The resulting products were neutralized to $\mathrm{pH}$ of 7 , by washing it several times with distilled water, and was oven dried at $105^{\circ} \mathrm{C}$ for $12 \mathrm{~h}$. The product was pulverized to sizes of $0.1-0.2 \mathrm{~mm}$.

The modified adsorbents were labelled as sodium hydroxide activated carbon (SAC), zinc chloride activated carbon (ZAC) and phosphoric acid activated carbon (PAC) and stored in a tight container for further use. A control sample was prepared without impregnation and was labelled as control activated carbon (CAC) and stored for further used.

\section{Characterization of Adsorbents}

The physicochemical properties of the $P$. candelabrum stem as performed using the elemental analyzer and American Standard for Testing Materials, standard test methods (Yorgun \& Yildiz, 2015, Shamsuddin et al., 2016). Scanning electron microscope (SEM)-energy dispersive X-ray (EDX), (SEM-EDX, JEOLJSM 7600F) was used to determine the morphology and elemental composition. Thermo Electron Nicolet 4700 FTIR spectrometer recorded the spectra of the adsorbent from 4000 to $500 \mathrm{~cm}^{-1}$ resolution. The Brunauer-Emmett Teller (BET) method was used to determine specific surface area and pore volume using a micromeritics ASAP 2020. Methylene blue (MB) and iodine were used to test the adsorption capacities of adsorbents. For MB, about $250 \mathrm{mg}$ of adsorbents were mixed with 25 $\mathrm{mL}$ of $1.5 \mathrm{~g} / \mathrm{L}$ MB standard solution and shaken at $250 \mathrm{rpm}$ in a thermostatic shaker at $25{ }^{\circ} \mathrm{C}$ for $24 \mathrm{~h}$ (Liu et al., 2019). While iodine value was tested by mixing $250 \mathrm{mg}$ of adsorbents with $25 \mathrm{~mL}$ of $0.10 \mathrm{~N}$ iodine solution, and was shaken for $30 \mathrm{~min}$, and then iodine adsorption amount was determined by titration against standard $\mathrm{Na}_{2} \mathrm{~S}_{2} \mathrm{O}_{3}$ (Liu et al., 2019). The MB and iodine adsorption amount of AC was determined according to Sahira et al., (2013), Hassan et al., (2014) and Liu et al., (2019).

\section{RESULTS \& DISCUSSION}

\section{Characterization of Adsorbents}

The result of characteristion of $P$. candelabrum stem are presented in Table 1 . The stem was found to have moisture content of $4.99 \%$, ash content of $6.32 \%$, which was low, and volatile matter of $72.3 \%$, which was high. As seen from Table 1, the 
Table 1. The properties of Pandanus candelabrum stem

\begin{tabular}{llll}
\hline Proximate analysis (\%) & \multicolumn{3}{c}{ Ultimate Analysis (\%) } \\
\hline Fixed carbon & 12.00 & $\mathrm{C}$ & 45.04 \\
Moisture content & 4.99 & $\mathrm{H}$ & 6.72 \\
Ash content & 6.32 & $\mathrm{~N}$ & 0.42 \\
Volatile matter & 72.30 & $\mathrm{O}$ & 43.85 \\
\hline
\end{tabular}

Table 2. Physicochemical properties of adsorbent

\begin{tabular}{lllll}
\hline Parameter & CAC & SAC & ZAC & PAC \\
\hline Ash content $(\%)$ & 11.663 & 17.622 & 11.554 & 13.095 \\
Moisture Content $(\%)$ & 7.784 & 4.382 & 0.994 & 0.994 \\
Bulk density $\left(\mathrm{g} / \mathrm{cm}^{3}\right)$ & 0.354 & 0.444 & 0.259 & 0.316 \\
\hline
\end{tabular}

high volatile matter and low ash content of $P$. candelabrum stem has made it suitable as an alternative starting material for production of activated carbon.

The results of adsorbent characterization are presented in Table 2. The activated carbon produced from Pandanus stem with different agents had different properties. The SAC had the highest ash content (17.62), bulk density (0.444 $\mathrm{g} / \mathrm{cm}^{3}$ ) and low pore volume (1.220), while ZAC has the lowest bulk density $\left(0.259 \mathrm{~g} / \mathrm{cm}^{3}\right)$ and ash content $(11.554 \%)$. The increase in bulk density is because of the decrease in pore volume of the activated carbons which resulted to increase in weight of the absorbents. The presence of low volatile content may have contributed to the formation of large quantity of non-volatile matter such as ash (Kilic et al., 2012). The properties of adsorbent obtained are in comparison with previous findings by some researchers (Ademuliyi et al., 2016).

Figure 1 shows the surface areas, pore volumes and amount of adsorbed methylene blue and iodine for adsorbents activated with different chemical agents. The surface area is $2648 \mathrm{~m}^{2} / \mathrm{g}$ for PAC, $1482.9 \mathrm{~m}^{2} / \mathrm{g}$ for SAC, $1114.13 \mathrm{~m}^{2} / \mathrm{g}$ for ZAC and $43.22 \mathrm{~m}^{2} / \mathrm{g}$ for CAC. Pore volume is $1.683 \mathrm{~cm}^{3} / \mathrm{g}$ for PAC, $1.448 \mathrm{~cm}^{3} / \mathrm{g}$ for SAC, $1.220 \mathrm{~cm}^{3} / \mathrm{g}$ for $\mathrm{ZAC}$ and $1.046 \mathrm{~cm}^{3} / \mathrm{g}$ for CAC. In Figure 1, surface area (Figure 1a) and pore volume (Figure 1b), phosphoric had the highest surface area and pore volume, which is $2648 \mathrm{~m}^{2} / \mathrm{g}$ and $1.683 \mathrm{~cm}^{3} / \mathrm{g}$ respectively. The highest surface area of PAC may be due to $\mathrm{H}_{3} \mathrm{PO}_{4}$ interaction decomposed some component in the carbon source, such as aliphatic and aromatic compounds, and this resulted in easy gasification of volatile matters (Kilic et al., 2012). The trends therefore, imply that the accessible area of adsorbent available for methylene blue adsorption follows the decreasing order, PAC > ZAC $>$ SAC $>$ CAC. The properties of adsorbents will favour adsorption.

From Figure 1c, the amount of iodine value and methylene blue adsorbed, is 541 and $105 \mathrm{mg} / \mathrm{g}$ for PAC, 175 and $36 \mathrm{mg} / \mathrm{g}$ for SAC, 128 and $16 \mathrm{mg} / \mathrm{g}$ for ZAC and 118 and $13 \mathrm{mg} / \mathrm{g}$ for CAC respectively. It can be observed that adsorption of iodine show increasing in adsorption capacity in the following decreasing order: $\mathrm{PAC}>\mathrm{SAC}>\mathrm{ZAC}$ $>$ CAC. This shows capability of each adsorbent to adsorb small sized atom such as iodine (Nunes $e t$ $a l ., 2011)$. In addition, it can be seen from Figure $1 \mathrm{c}$, PAC had the maximum iodine value and methylene blue $(541 \mathrm{mg} / \mathrm{g}$ of carbon and 105 $\mathrm{mg} / \mathrm{g}) . \mathrm{H}_{3} \mathrm{PO}_{4}$ aids in the degradation of carbon sources as well as in the creation of structures that exhibit cross-linking properties (Budinova et al., 2006). And this will lead to the development of pores of micro and meso sizes in the adsorbent (Danish et al., 2014, Yorgun \& Yildiz, 2015).

The highest iodine value by PAC may be due to the presence of large micropores in the adsorbent (Moreno-Virgen et al., 2012). This is followed by SAC which has iodine value of $175 \mathrm{mg} / \mathrm{g}$. Here both micro porosity and mesoporosity were created through segregation and decomposition of graphite layers due to reduction and oxidative transformation. This aids volatilization, that disintegrates the matrix resulting to increased surface area available for adsorption (Foo \& 

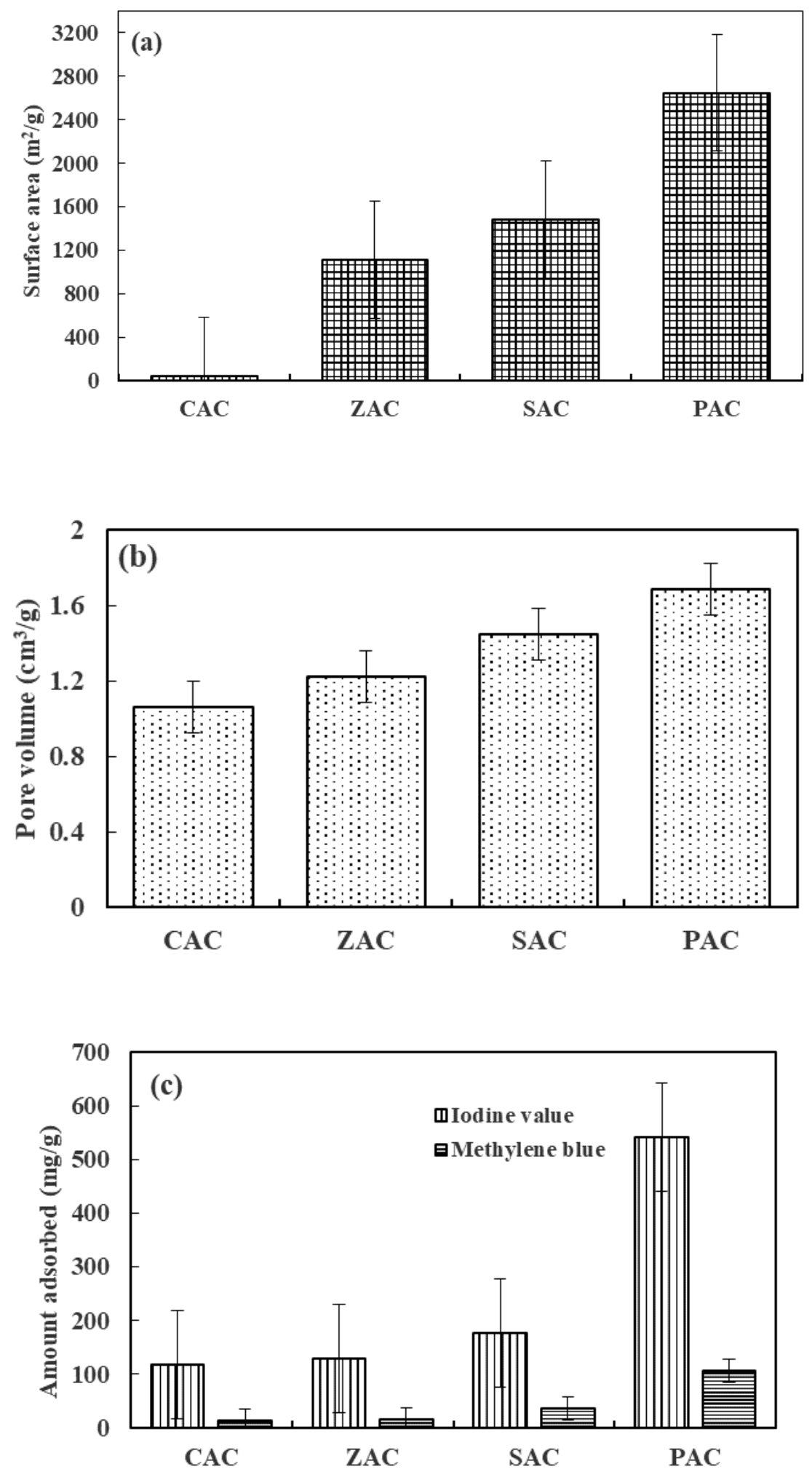

Figure 1. Surface areas (a), pore volumes (b) and amount of adsorbed methylene blue and iodine value (c) for carbon activated with different chemical agents 
Hameed, 2012). While ZAC and CAC have iodine value of 128 and $118 \mathrm{mg} / \mathrm{g}$ of carbon respectively. In Figure 1c, it can also be observed that the adsorbents show the adsorption ability decreased in the following order: $\mathrm{PAC}>\mathrm{SAC}>\mathrm{ZAC}>\mathrm{CAC}$. In this context the ability to adsorbed methylene blue shows how each activated carbon will adsorb large molecules such as methylene blue which is much larger than iodine molecules (Cleiton et al., 2011). PAC impregnated with $\mathrm{H}_{3} \mathrm{PO}_{4}$ has the highest adsorption value of $105 \mathrm{mg} / \mathrm{g}$ for methylene blue. This suggests it has welldeveloped mesopores and some portions of micropores (Shrestha et al., 2012).

\section{Scanning Electron Microscope (SEM) Analysis}

The micrograph for unmodified carbon (CAC) (Figure 2a) shows broad surface which consists of few pores, aggregates of small particles, with irregular shape, relatively rough surface, and without cavities. The micrographs of modified carbon (Figures 2b-d) of adsorbent particles showed cavities, pores and rough surfaces. There is more presence of pores with openings in the adsorbents synthesized with $\mathrm{H}_{3} \mathrm{PO}_{4}, \mathrm{NaOH}$ and $\mathrm{ZnCl}_{2}$ agents. The features on carbon surface revealed clearly the effect of activating agent on the textural properties. The pore openings are due to extraction of some materials from the surface by activating agents (Shamsuddin et al., 2015). The morphological features on the surface of adsorbent are the evidence of the effect of activating agents. PAC activated carbon impregnated with $\mathrm{H}_{3} \mathrm{PO}_{4}$ (Figure 2b) has more open pores and cavities. SAC and ZAC activated carbon (Figures $2 \mathrm{c}-\mathrm{d}$ ) also show presence of open pores. The various chemical agents lead to different reaction mechanisms which resulted to adsorbent with different pore structures. The mechanisms by which $\mathrm{H}_{3} \mathrm{PO}_{4}$ activates carbon source entails structural degradation and volatilization, whereas activation with $\mathrm{NaOH}$ and $\mathrm{ZnCl}_{2}$ aids the creation of porosity by the expulsion of water molecules present in the carbon precursor (Kilic et al., 2012).

\section{Energy Dispersive X-ray Analysis}

The unmodified carbon (CAC) and modified PAC, SAC and ZAC were evaluated using EDX (Table $3)$. The analysis showed that carbon content increased from 82.01 to $86.38 \%$, in the order of $\mathrm{CAC}<\mathrm{ZAC}<\mathrm{SAC}<\mathrm{PAC}$.
The decrease in oxygen content was from 4.06 $\%$ to $2.32 \%$, the trend was in the order of CAC < SAC $<$ ZAC $<$ PAC. But it was observed that SAC had the highest oxygen content among the modified activated carbon. This could suggest that $\mathrm{NaOH}-$ activated carbon has functional groups which contain more oxygen atom. SAC has the highest oxygen content of $3.79 \%$ among all the chemical activated carbon. The high oxygen content of $\mathrm{NaOH}$-activated carbon could be attributed to the oxidation of carbon precursor in alkaline environment (Huang \& Zhao, 2015). From Table 3, it can also be seen that other elements present in CAC, SAC, ZAC and PAC are calcium, nitrogen, potassium, silicon, phosphorus, aluminium, sulphur, magnesium, sodium and chlorine.

\section{XRD Analysis}

The diffractogram of SAC, ZAC and PAC in comparison with $\mathrm{CAC}$ are shown in Figure 3. Activating agents and carbonization caused changes in the crystal structure of the carbons. The CAC displayed peaks at approximately $26.6^{\circ}$, $31.2^{\circ}, 32.1^{\circ}$ and $49.5^{\circ}$, this indicates the presence of graphite (Wang et al., 2009). In comparison with CAC, all the chemically activated carbons show peaks at about $26.7^{\circ}, 33.1^{\circ}, 34.2^{\circ}, 36.6,39.2^{\circ}$, $46.8^{\circ}, 50.2^{\circ}, 60.1^{\circ}$ and $68.3^{\circ}$ respectively. The peak intensity changed the activation and subsequent carbonization and this made the peaks look sharper and wider.

This suggests that activated carbons prepared with agents resulted in the formation of micro crystallites which are like graphite (Wang et al., 2011). Therefore, the increase in pore size is because the pore walls are made of hexagonal graphitic microcrystalline which were disintegrated severely. The emergence of new diffractogram pattern shows the creation of new amorphous and crystalline planes (Huang \& Zhao, 2015).

\section{FTIR Surface Analysis}

The surface chemical properties of the adsorbents were examined using FTIR analysis. Figure 4 shows the spectrum of the adsorbent obtained without chemical activation (CAC) and the spectra for those obtained with chemical activation (ZAC, SAC and PAC. Similarity as well as difference exist in the absorption pattern of the produced 


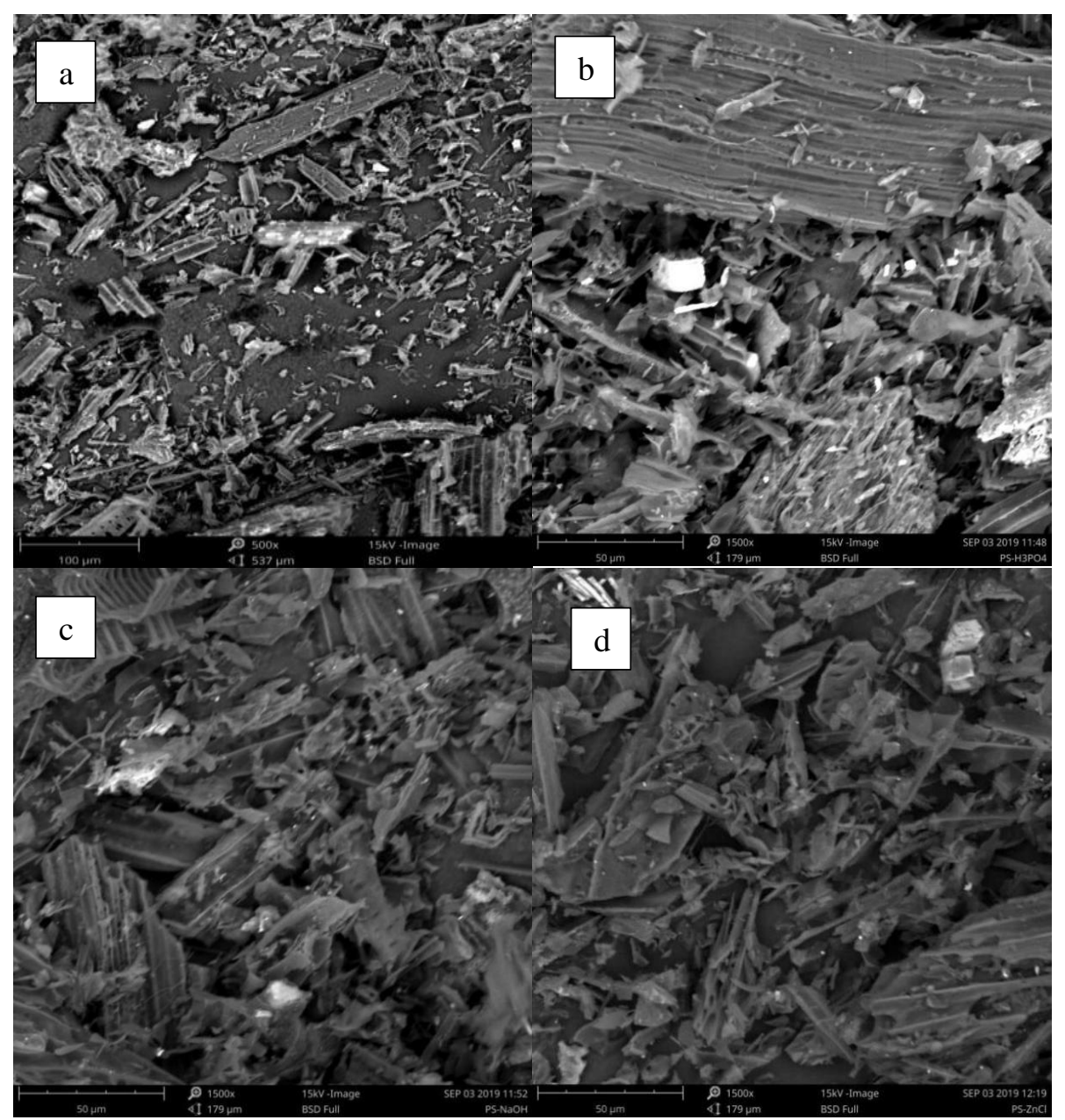

Figure 2. SEM micrograph for activated carbons, (a) Control activated carbon (CAC), (b) Zinc chloride activated carbon (ZAC), (c) sodium hydroxide activated carbon (SAC), (d) Phosphoric acid activated carbon (PAC)

Table 3. Elemental analysis of activated carbons

\begin{tabular}{ccccccc}
\hline $\begin{array}{c}\text { Element } \\
\text { name }\end{array}$ & $\begin{array}{c}\text { Element } \\
\text { symbol }\end{array}$ & $\begin{array}{c}\text { Proton } \\
\text { number }\end{array}$ & $\begin{array}{c}\mathrm{CAC} \\
\mathrm{Wt}(\%)\end{array}$ & $\begin{array}{c}\text { ZAC } \\
\mathrm{Wt}(\%)\end{array}$ & $\begin{array}{c}\text { SAC } \\
\mathrm{Wt}(\%)\end{array}$ & $\begin{array}{c}\text { PAC } \\
\mathrm{Wt}(\%)\end{array}$ \\
\hline Carbon & $\mathrm{C}$ & 6 & 82.01 & 83.10 & 84.42 & 86.38 \\
Oxygen & $\mathrm{O}$ & 8 & 4.06 & 2.79 & 3.79 & 2.32 \\
Calcium & $\mathrm{Ca}$ & 20 & 3.22 & 4.20 & 4.12 & 4.02 \\
Nitrogen & $\mathrm{N}$ & 7 & 1.85 & 0.20 & 1.45 & 1.01 \\
Potassium & $\mathrm{K}$ & 19 & 1.38 & 0.84 & 0.79 & 1.15 \\
Silicon & $\mathrm{Si}$ & 14 & 1.35 & 2.21 & 1.63 & 1.52 \\
Phosphorus & $\mathrm{P}$ & 15 & 1.16 & 1.20 & 1.56 & 2.03 \\
Aluminium & $\mathrm{Al}$ & 13 & 0.65 & 0.83 & 0.60 & 0.46 \\
Sulphur & $\mathrm{S}$ & 16 & 0.63 & 0.71 & 0.42 & 0.36 \\
Magnesium & $\mathrm{Mg}$ & 12 & 0.57 & 0.81 & 0.78 & 0.58 \\
Sodium & $\mathrm{Na}$ & 11 & 0.13 & 0.55 & 0.45 & 0.18 \\
Chlorine & $\mathrm{Cl}$ & 17 & 0.00 & 0.63 & 0.00 & 0.00 \\
\hline
\end{tabular}



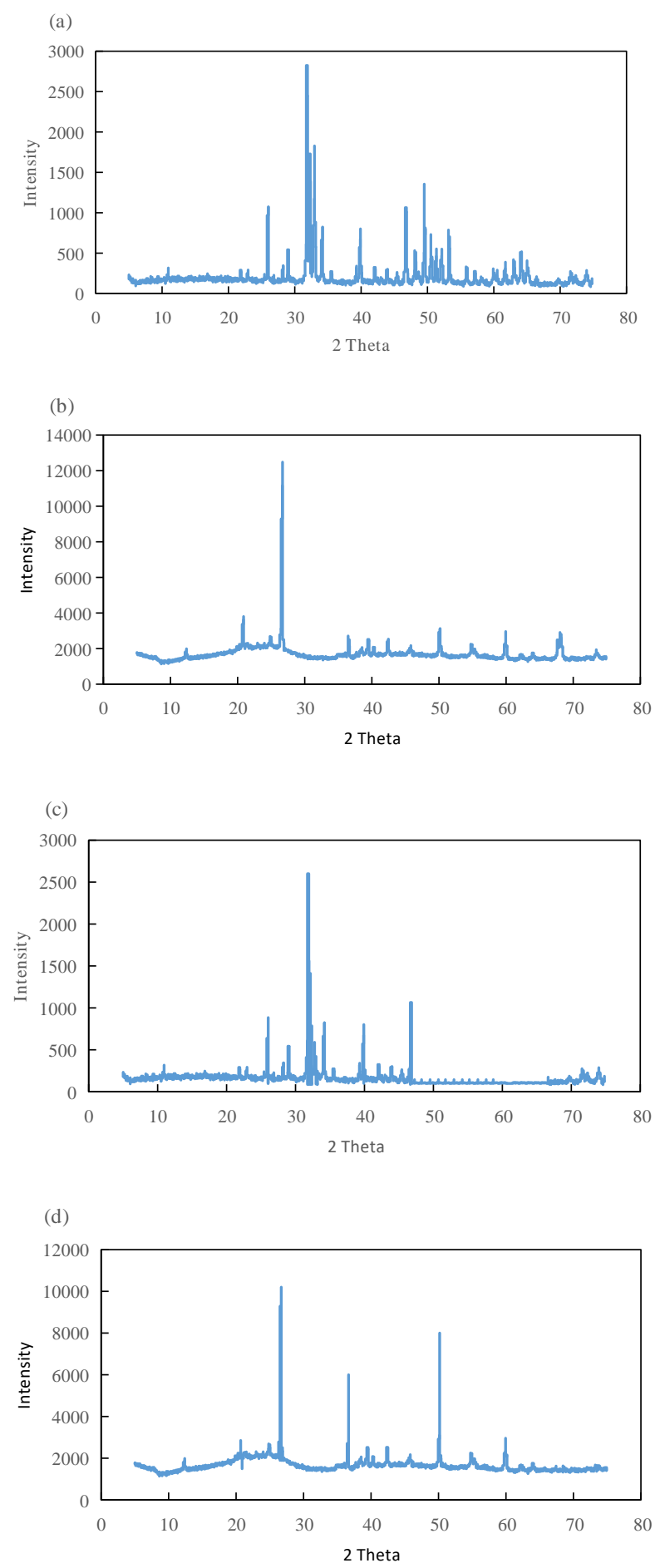

Figure 3. XRD for activated carbons: (a) Control activated carbon (CAC), (b) Zinc chloride activated carbon (ZAC), (c) sodium hydroxide activated carbon (SAC), (d) Phosphoric acid activated carbon (PAC) adsorbents. The weak absorption band at 3900$3600 \mathrm{~cm}^{-1}$ are present in all the carbon spectra. This is assigned to hydroxyl bonds (Yakout \& El-Deen, 2016). For CAC, the peak indicates the presence of $\mathrm{O}-\mathrm{H}$ alcoholic group which was observed at the absorption around $3851 \mathrm{~cm}^{-1}$. The absorption peak at 2923 and $2853 \mathrm{~cm}^{-1}$ corresponds to aliphatic stretch vibration and $\mathrm{C}-\mathrm{H}$ functional group (Norouzi et al., 2018). Those weak peaks observed around $2360.52-2343.44 \mathrm{~cm}^{-1}$ are assigned to the $\mathrm{O}-\mathrm{H}$ group showing the presence of phenyl group. While the band observed at $1564 \mathrm{~cm}^{-1}$ indicates $\mathrm{C}=\mathrm{C}$ bond showing the presence of carbon in aromatic structure (Kilic et al., 2012). The peaks at 1462.40 and $1377.01 \mathrm{~cm}^{-1}$, correspond to methyl group. The little peak at $1154-1250 \mathrm{~cm}^{-1}$ could be ascribed to $\mathrm{C}-\mathrm{C}$ and $\mathrm{C}-\mathrm{O}$ stretched vibrations. These positions indicate the presence of acidic, alcohols, phenols, esters and ether group. The peaks at 668 and $721.61 \mathrm{~cm}^{-1}$ indicate the presence of aromatic structures (Wang et al., 2014). This indicates that CAC contains methyl, aromatic and ester bonds which have the presence of oxygen species.

The spectra of PAC, SAC and ZAC indicates reduction in absorption peaks of functional groups. Irrespective of the activating agent used, the spectra were slightly different in the absorption patterns. The weak transmittance bands at 3851$3667 \mathrm{~cm}^{-1}$ exhibited by all the carbons, which is the presence of hydroxyl group. This weak intensity shows that the precursor was dried properly. The bands at 2853, 2923, 1462 and $1377 \mathrm{~cm}^{-1}$ are shrink or reduced for all the modified carbons. While the bands observed at 2343, 2360, 1154, 721 and 668 $\mathrm{cm}^{-1}$ disappeared for all the chemically activated carbon. This absorption illustrates the presence of active carbon in the prepared samples. Furthermore, in PAC, SAC and ZAC the elimination and reduction of some peaks suggests the decomposition and modification of surface chemistry by carbonization and chemical activation. These results suggest that concurrent carbonization and chemical activation caused the formation of new species and decomposition of many bonds that are weak in the functional group (Deng et al., 2010). 


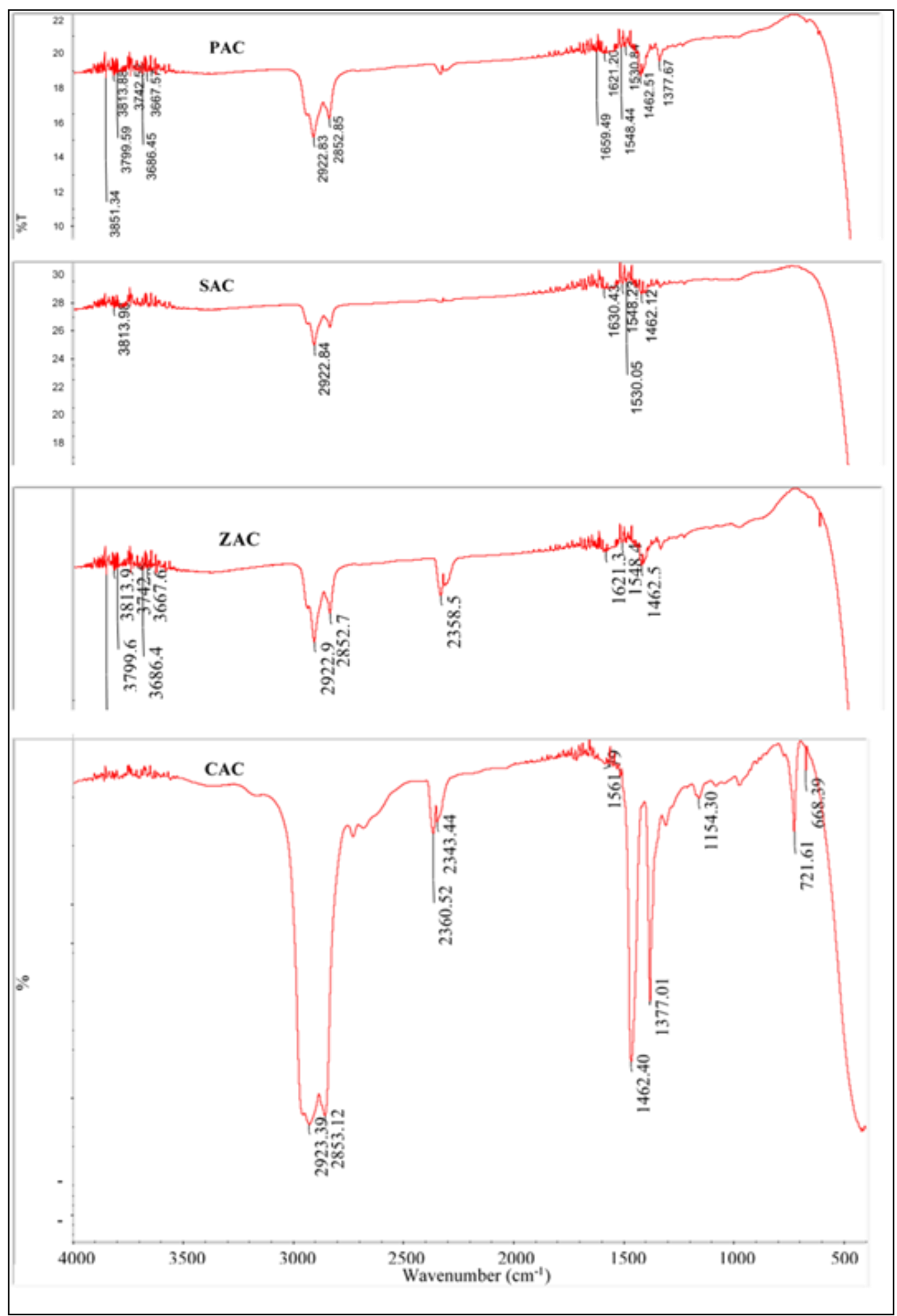

Figure 4. FTIR spectrum of CAC, ZAC, SAC and PAC 


\section{CONCLUSION}

Pandanus candelabrum stem has been utilized to produce activated adsorbent using different chemical agents. The effect of agents on the proprieties of the adsorbent were investigated. FTIR results indicate that all the adsorbent prepared has some similarity and differences on the nature of their surface chemical properties. SEM micrograph of adsorbents impregnated with chemical agents showed well-developed pores structure compared to unmodified carbon. The study revealed that chemical agents had effect on the properties of the modified adsorbents. They showed increase in the adsorption of methylene blue in the order of CAC $<\mathrm{ZAC}<\mathrm{SAC}<\mathrm{PAC}$, and iodine number is in the increasing order of $\mathrm{CAC}<\mathrm{ZAC}<\mathrm{SAC}<\mathrm{PAC}$. This shows that PAC $\left(\mathrm{H}_{3} \mathrm{PO}_{4}\right)$ activated carbon had the highest iodine number and methylene blue $(541 \mathrm{mg} / \mathrm{g}$ of carbon and $105 \mathrm{mg} / \mathrm{g}$ ). The surface area is $2648 \mathrm{~m}^{2} / \mathrm{g}$ for PAC, $1482.9 \mathrm{~m}^{2} / \mathrm{g}$ for SAC, $1114.13 \mathrm{~m}^{2} / \mathrm{g}$ for ZAC and $43.22 \mathrm{~m}^{2} / \mathrm{g}$ for CAC. Pandanus candelabrum stem is an alternative lignocellulosic source that can be used to synthesize high porous adsorbent, which is abundant, easy to access, inexpensive and readily available.

\section{REFERENCES}

Ademiluyi, F. T. \& Nze, J. C. (2016). Multiple adsorption of heavy metal ions in aqueous solution using activated carbon from Nigerian Bamboo. International Journal of Research in Engineering and Technology, 5 (1): 164-169.

Akpabio U.D. \& Akpakpan, A.E. (2012). Pulp and paper from agricultural wastes: Plantain pseudostem wastes and screw pine leaves. International Journal of Modern Chemistry, 2 (3):100-107.

Baba, S., Hung, T. C., Mio, K.., Tomomi, I. \& Eric, W. C. C. (2016). Artocarpus altilis and Pandanus tectorius: Two important fruits of oceania with medicinal values. Journal of Food and Agriculture, 28 (8): 531-539.

Budinova, T., Ekinci, E., Yardım, F., Grimm, A., Björnborn, E. \& Minkova, V. (2006). Characterization and application of activated carbon produced by $\mathrm{H}_{3} \mathrm{PO}_{4}$ and water vapor activation. Fuel Process Technology, 87:899-905.
Cadavid, Y., Cadena, E.M., Velez, J.M. \& Santa, J.F. (2016). Degradation of dyes using plantain fibers modified with nanoparticles. In R. Fangueiro and S. Rana (eds.), Natural Fibres: Advances in Science and Technology Towards Industrial Applications, RILEM Book series 12. pp.99-112.

Cleiton, N. A. \& Guerreiro, M. C. (2011). Estimation of surface area and pore volume of activated carbons by methylene blue and iodine numbers. Quím. Nova, 34 (3): 421-432.

Danish, M., Hashim, R., Ibrahim, M.N.M. \& Sulaimon, O. (2014) Optimization study for preparation of activated carbon from Acacia magnum wood using phosphoric acid. Wood Science and Technology, 48: 1069-1083.

Deng, H., Li, G.X., Yang, H.B., Tang, J.P. \& Tang, J.Y. (2010). Preparation of activated carbons from cotton stalk by microwave assisted $\mathrm{KOH}$ and $\mathrm{K}_{2} \mathrm{CO}_{3}$ activation. Chemical Engineering Journal, 163: 373-381.

Dim, P.E. (2013). Adsorption of methyl red and methyl orange using different tree bark powder, Academic Research International, 4:(1) 330-338.

Dim, P.E., Olu, S.C. \& Okafor, J.O. (2020). Kinetic and thermodynamic study of adsorption of $\mathrm{Cu}$ (II) and $\mathrm{Cr}$ (VI) ion from industrial effluent onto kaolinite clay. Journal of Chemical Technology and Metallurgy, 55 (5) : 1057-1067.

Fillaeli, A., Kristianingrum, S., Siswani, E. D. \& Fatimah S. D. (2019). Synthesis activated carbon of screw-pine leaves by $\mathrm{HNO}_{3}$ and its properties. Journal of Physics: Conf. Series 1156 (2019) 01200. doi:10.1088/1742-6596/1156/1/012001 (Accessed: 20 September 2020).

Foo, K.Y. \& Hameed, B.H. (2012). Potential of jackfruit peel as precursor for activated carbon prepared by microwave induced $\mathrm{NaOH}$ activation. Bioresource Technology, $112: 143-150$.

Giraldo, L., Rodriguez-Estupiñan, P. \& MorenoPiraján. J.C. (2018). A microcalorimetric study of methane adsorption on activated carbons obtained from mango peel at different conditions. Journal of Thermal Analysis and Calorimetry, 166: 552 - 556.

Gu, Z. \& Wang, X. (2013). Carbon materials from high ash bio-char: a nanostructure similar to activated graphene. American Transactions on Engineering and Applied Sciences, 2:15 - 34. 
Hassan, A.F., Abdel-Mohsen, A.M. \& Fouda, M.M.G. (2014). Comparative study of calcium alginate, activated carbon, and their composite beads on methylene blue adsorption. Carbohydrate Polymers, 102 (1): 192-198.

Huang, Y. \& Zhao, G. (2015). Preparation and characterization of activated carbon fibers from liquefied wood by $\mathrm{KOH}$, Holzforschung, online, DOI: 10.1515/hf-2015-0051 (Accessed: 10 August 2020).

Hussein, T.K. \& Jasim, N.A. (2019). Removal of crystal violet and methylene blue from synthetic industrial wastewater using fennel seed as an adsorbent. Journal of Engineering Science and Technology, 14 (5): 2947-2963.

Kılıç, M, Apaydın-Varol, E. \& Pütün, A.E. (2012). Preparation and surface characterization of activated carbons from Euphorbia rigida by chemical activation with $\mathrm{ZnCl}_{2}, \mathrm{~K}_{2} \mathrm{CO}_{3}, \mathrm{NaOH}$ and $\mathrm{H}_{3} \mathrm{PO}_{4}$. Applied Surface Science, 261: 247-254.

Kumar, A. \& Jena, H. M. (2017). Removal of methylene blue and phenol onto prepared activated carbon from fox nutshell by chemical activation in batch and fixed bed column. Journal of Cleaner Production, 137:1246-1259.

Liu, Y., Yao, X., Wang, Z., Li, H., Shen, X., Yao, Z. \& Qian, F. (2019). Synthesis of activated carbon from citric acid residue by phosphoric acid activation for the removal of chemical oxygen demand from sugar-containing wastewater. Environmental Engineering Science, 36 (6): 656-666.

Moreno-Virgen, M.D.R., Tovar-Gomez, R., MendozaCastillo, D.I. \& Bonilla-Petriciolet, A. (2012). Applications of activated carbons obtained from lignocellulosic materials for the wastewater treatment, Instituto Tecnológico de Aguascalientes México, DOI: 10.5772/39367 (Accessed: 22 August 2020).

Mario, A. T. \& Hiromitsu, T. (2018). Chemistry of Pandanus alkaloids. International Journal of Chemistry and Biology, 82: 1-28.

Nafsun, A.I., Nasir, A.J., Jamal, M.N.M., Mohamad, S., Abdulrazik, A., Raja, D.D.S. \& Herz, F. (2020). Influence of activation temperature and acid concentration on sludge-based activated carbon, IOP Conf. Ser.: Material Science and Engineering, 872012064
Norouzi, S., Heidari, M., Alipour, V., Rahmanian, O., Fazlzadeh, M., Mohammadi-Moghadam, F., Nourmoradi, H., Goudarzi, B. \& Dindarloo, K. (2018). Preparation, characterisation and $\mathrm{Cr}$ (VI) adsorption evaluation of $\mathrm{NaOH}$ activated carbon produced from Date Press Cake: An agro-industrial waste, Bioresource Technology, 258: 48-56.

Nunes, C.A. \& Guerreiro, M.C. (2011). Estimation of surface area and pore volume of activated carbons by methylene blue and iodine numbers. Quimica Nova, 34(3): 472-476.

Rai, M.K., Shahi, G., Meena, V., Meena, R., Chakraborty, S., Singh, R.S. \& Rai, B.N. (2016). Removal of hexavalent chromium Cr (VI) using activated carbon prepared from mango kernel activated with $\mathrm{H}_{3} \mathrm{PO}_{4}$. Resource-Efficient Technologies, 2: 63-70.

Ramavandi, B. \& Asgari, G. (2018). Comparative study of sun-dried and oven-dried Malva sylvestris biomass for high-rate $\mathrm{Cu}$ (II) removal from wastewater. Process Safety and Environmental Protection, 116: 61-73.

Sahira, J., Mandira, A., Prasad, P.B. \& Ram, P.R. (2013). Effects of Activating Agents on the Activated Carbons Prepared from Lapsi Seed Stone. Research Journal of Chemical Sciences, 3(5): 19-24.

Shamsuddin, N.S., Yusoff, N.R.N. \& Sulaiman, M.A. (2016). Synthesis and characterization of activated carbon produced from kenaf core fibre using $\mathrm{H}_{3} \mathrm{PO}_{4}$ activation. Procedia Chemistry, 19: 558 - 565.

Shrestha, R.M., Yadav, A.P., Pokharel, B.P. \& Pradhananga, R. (2012). Preparation and characterization of activated carbon from Lapsi (Choerospondias axillaris) seed stone by chemical activation with phosphoric acid. Research Journal of Chemical Sciences, 2(10): 80-86.

Wang, T.H., Tan, S.X. \& Liang, C.H. (2009) Preparation and characterization of activated carbon from wood via microwave-induced $\mathrm{ZnCl}_{2}$ activation. Carbon, 47: 1867-1885.

Wang, Z., Wu, J., He, T. \& Wu, J. (2014). Corn stalks char from fast pyrolysis as precursor material for preparation of activated carbon in fluidized bed reactor. Bioresource Technology, 167: 551-554. 
Wang, Z., Nie, E., Li, J. Zhao, Y., Luo, X. \& Zheng, Z. (2011). Carbons prepared from Spartina alterniflora and its anaerobically digested residue by $\mathrm{H}_{3} \mathrm{PO}_{4}$ activation: characterization and adsorption of cadmium from aqueous solutions. Journal of Hazardous Materials, 188: 29-36.

Yakout, T.M. \& El-Deen, G.S. (2016) Characterization of activated carbon prepared by phosphoric acid activation of olive stones. Arabian Journal of Chemistry, 9: 1155-1162.
Yorgun, Y. \& Y1ldiz, D. (2015). Preparation and characterization of activated carbons from Paulownia wood by chemical activation with $\mathrm{H}_{3} \mathrm{PO}_{4}$. Journal of the Taiwan Institute of Chemical Engineers, 24: 1-10.

Zubrik, A., Matik, M., Hredzák, S., Lovás, M., Danková, Z., Kováčová, M. \& Briančin, J. (2017). Preparation of chemically activated carbon from waste biomass by single-stage and two-stage pyrolysis, Journal of Cleaner Production, 137: 1236-1249. 